\title{
Effect of Tranexamic Acid on Blood Loss in Elective Cesarean Delivery
}

\author{
Esmail Talaat Al-Garhy, Ashraf Hamdy Mohamed, and Islam Abdullatif Barakat*
}

Department of Obstetrics and Gynecology, Faculty of Medicine, Al-Azhar University

*Corresponding author: Islam Abdullatif Barakat, Mobile: (+20)01229702442, Email: islam.barakat@ hotmail.com

Abstract

Background: tranexamic acid as an agent given before surgical procedures reduces the blood transfusion risk, mean volume lost, and the requirement for reintervention due to bleeding issues, without raising thrombotic risks.

Aim: to evaluate Tranexamic acid agent infusion as regards its efficacy in blood volume loss reduction in practice of elective lower segment cesarean section delivery.

Patients and Methods: A double blinded, randomized, controlled research clinical trial. All study subjects have been recruited from the cases scheduled for elective cesarean delivery in the labor ward of Mokattam Insurance Hospital. The study subjects were totally 200 cases allocated in by randomization into 2 research groups. The study research group have been composed of 100 cases that were administered a mixture of tranexamic acid $25 \mathrm{mg} / \mathrm{kg}$ in $200 \mathrm{ml}$ of normal saline by intravenous drip for 20 minutes before incision, while the control research group contained 100 cases administered a volume of normal saline in accordance to patient's weight $(25 \mathrm{mg} / \mathrm{kg})$ by intravenous drip for 20 minutes before time of incision.

Results: Blood loss volume was statistically significantly lower among Tranexamic research group than among placebo research group ( $\mathrm{p}$ value $<0.001$ ). Postoperative hematocrit was statistically significantly higher among Tranexamic research group than among placebo research group ( $p$ value $=0.020$ ). Hematocrit reduction was statistically significantly lower among Tranexamic research group than among placebo research group ( $\mathrm{p}$ value $<0.001$ ). PPH and blood transfusion were statistically significantly less frequent among Tranexamic research group ( $\mathrm{p}$ values $=0.010,0.005$ consecutively).

Conclusions and Recommendation: The administration of tranexamic acid before starting a cesarean section is valuable as a prophylaxis against intra-operative and post-partum bleeding issues.

Future research studies are required to consider various variables such as racial and ethnic differences and consider various clinical case scenarios e.g. previous cesarean delivery and categorization of more possible critical indications of cesarean such as second stage cesarean, emergency cesarean section and time interval of decision to incision as those variables could influence blood volume loss indices.

\section{Introduction}

Postpartum hemorrhage is defined clinically as blood loss of $500 \mathrm{cc}$ or more within 24 hours after delivery. Statistical estimates of its incidence in the research studies differ widely, from $3 \%$ to $15 \%$ of deliveries ${ }^{(1)}$. About one in five of these hemorrhages progress to severe form that could jeopardize maternal life or future fertility and causes hazardous risks exposure to issues transfusion, surgical intervention, and intensive care $\operatorname{admission}^{(2)}$. Post partum hemorrhage is considered a leading cause for maternal mortality and accounting for around $25 \%$ of all maternal mortalitiesglobally ${ }^{(3)}$. Its clinically expected risk factors involve prior history of post partum hemorrhage, multi parity, obesity, prolonged or augmented course of labor, multifetal gestation, prior cesarean mode of delivery, polyhydramnios, and macrosomia ${ }^{(\mathbf{4})}$. Tranexamic acid is a synthetic derivative of the amino acid lysine that has an antifibrinolytic pharmacological impactvia the reversible blockage of the lysine binding sites on plasminogen molecules ${ }^{(\mathbf{5})}$. Intravenous administration of Tranexamic acid have been routinely implemented for management and prevention of bleeding with satisfactory results research findings from previous research trials have displayed that Tranexamic acid in elective surgical procedure decreases the blood transfusion risk, mean volume transformed, and the requirement for re-operation due to active bleeding, without raising thrombotic events ${ }^{(6-}$ 10).

\footnotetext{
Aim

The current research main goal is to asses and evaluates Tranexamic Acid infusion as regards the efficiency in blood loss reduction during elective lower segment cesarean section delivery.
} 


\section{Patients and Methods}

The current research study is adouble blinded, randomized, controlled research trial. All study subjects have been recruited from the cases admitted for elective cesarean delivery in the labor ward of Mokattam Insurance Hospital. The research study performance was started after approval of research study protocol by Research and Ethical Committee of the department of Obstetrics and Gynecology, Faculty of Medicine, Al-Azhar University. A cohort of 200 cases have been recruited in the research study after clarifying the procedure and taking a written consent from every case that is going to participate in the research study. The cases have been randomized into 2 research groups. Study research group composed of 100 cases that will be administered a mixture of tranexamic acid $25 \mathrm{mg} / \mathrm{kg}$ in $200 \mathrm{ml}$ of normal saline intravenous drip 20 minutes before making the skin incision, control research group composed of 100 cases received a volume of normal saline according to patient's weight $(25 \mathrm{mg} / \mathrm{kg})$ intravenous drip 20 minutes before making the skin incision. Inclusive research criteria involved the following, case age from 25-40 years, BMI (20-28) $\mathrm{Kg} / \mathrm{m} 2$, Gestational age > 37 weeks, Singleton pregnancy. Exclusive research criteria, medical disorders: e.g. Hypertension, Diabetes mellitus, liver, kidney, Cardiac diseases, Pregnancy-induced disorders e.g. pre-eclampsia, eclampsia. Over distended uterus e.g. polyhydramnios, fetal macrosomia, accidental hemorrhage, Placenta previa,
Previous atonic postpartum hemorrhage, cases on medications: e.g. anticoagulants and antiplatelets, Multifetal gestations, pregnancy less than 37 weeks gestation, contraindications to tranexamic acid: e.g. Allergy, blood diseases. Estimation of blood loss by observation of blood loss by suction, towels and pads were placed under women buttocks then weighting the pads.

\section{Primary research outcome:}

The primary research outcome of this study is to investigate the reduction of blood loss $\leq 500 \mathrm{cc}$ as assessed by suction, towels, pads placed under women buttocks then weighting the pads to allow objective measurement of blood loss just after delivery of the baby.

\section{Secondary research outcome:}

Investigating and observing severe PPH (>1000 cc), the incidence of women requiring supplementary uterotonic agents, blood transfusion, or emergency surgery for treatment of PPH.

Only three patients needed blood transfusion, two patients had attack of $\mathrm{PPH}$, no mortality and four patients were excluded.

Written informed consent was obtained from all study subjects before recruitment in the study after explanation of the purpose and procedures of the study. 


\section{Results}

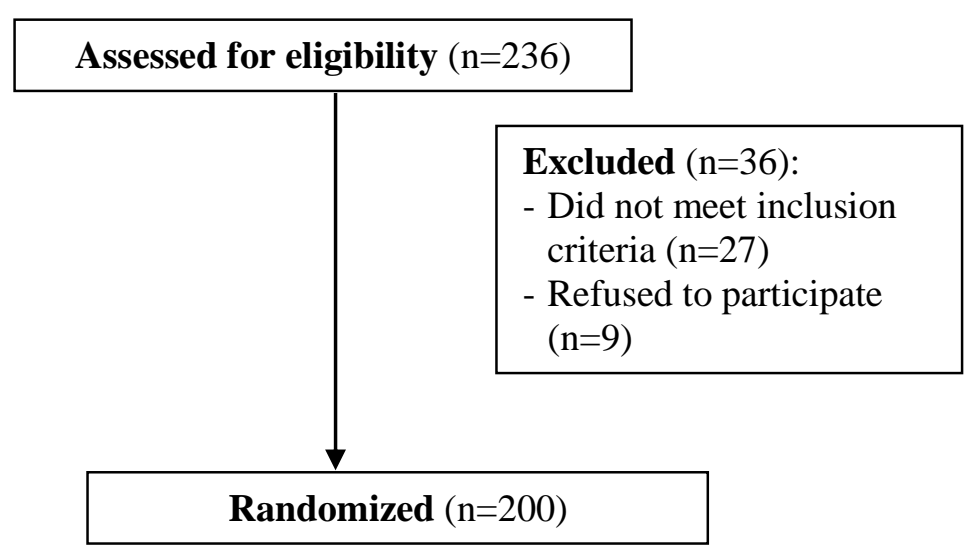

\section{Allocated to Tranexamic acid} group $(n=100)$

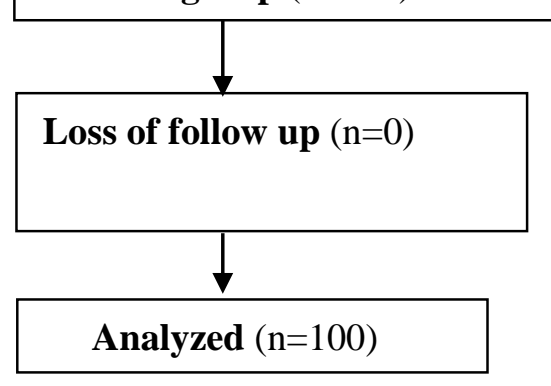

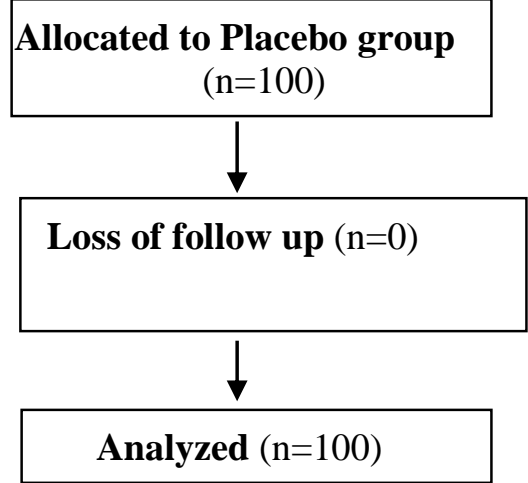

Figure (1): CONSORT, Patient flow chart. 
Table (1): Demographic characteristics among the studied groups

\begin{tabular}{|c|c|c|c|c|}
\hline Items & Measure & $\begin{array}{c}\text { Tranexamic } \\
(\mathrm{N}=100)\end{array}$ & $\begin{array}{l}\text { Placebo } \\
(\mathrm{N}=100)\end{array}$ & $\mathbf{P}$ \\
\hline \multirow{2}{*}{$\begin{array}{c}\text { Age } \\
\text { (years) }\end{array}$} & Mean \pm SD & $31.8 \pm 3.8$ & $32.5 \pm 3.4$ & \multirow{2}{*}{$\wedge^{\wedge} 0.174$} \\
\hline & Range & $25.0-40.0$ & $26.0-40.0$ & \\
\hline \multirow{2}{*}{$\underset{\left(\mathrm{kg} / \mathrm{m}^{2}\right)}{\mathrm{BMI}}$} & Mean \pm SD & $24.2 \pm 1.2$ & $24.1 \pm 1.2$ & \multirow{2}{*}{$\wedge 0.658$} \\
\hline & Range & $20.6-27.3$ & $20.4-26.8$ & \\
\hline \multirow{2}{*}{$\begin{array}{c}\text { GA } \\
\text { (weeks) }\end{array}$} & Mean \pm SD & $39.3 \pm 1.0$ & $39.2 \pm 1.2$ & \multirow{2}{*}{$\wedge 0.424$} \\
\hline & Range & $37.0-42.0$ & $37.0-42.0$ & \\
\hline \multirow{6}{*}{ 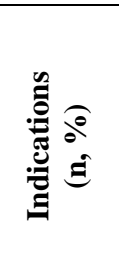 } & Dystocia & $36(36.0 \%)$ & $39(39.0 \%)$ & \multirow{6}{*}{ \#0.893 } \\
\hline & Fetal distress & $26(26.0 \%)$ & $27(27.0 \%)$ & \\
\hline & Malpresentation & $20(20.0 \%)$ & $14(14.0 \%)$ & \\
\hline & Prolonged labor & $10(10.0 \%)$ & $12(12.0 \%)$ & \\
\hline & CPD & $6(6.0 \%)$ & $5(5.0 \%)$ & \\
\hline & Others & $2(2.0 \%)$ & $3(3.0 \%)$ & \\
\hline
\end{tabular}

$\wedge$ Independent t-test, \#Chi square test

No significant statistical difference between the studied groups regarding demographic characteristics (age, BMI, Gestational age, indications for cesarean section p values $=0.174,0.658$, $0.424,0.893$, consecutively).

Table (2): Hemoglobin (gm/dL) among the studied groups

\begin{tabular}{|c|c|c|c|c|}
\hline Variable & Measure & $\begin{array}{c}\text { Tranexamic } \\
(\mathrm{N}=100)\end{array}$ & $\begin{array}{l}\text { Placebo } \\
(\mathrm{N}=100)\end{array}$ & ${ }^{\wedge} \mathbf{P}$ \\
\hline \multirow{2}{*}{$\begin{array}{c}\text { Pre } \\
\text { operative }\end{array}$} & Mean \pm SD & $12.5 \pm 0.8$ & $12.6 \pm 0.9$ & \multirow{2}{*}{0.258} \\
\hline & Range & $10.6-14.3$ & $10.3-14.4$ & \\
\hline \multirow{2}{*}{$\begin{array}{c}\text { Post } \\
\text { operative }\end{array}$} & Mean \pm SD & $11.7 \pm 0.8$ & $11.4 \pm 0.9$ & \multirow{2}{*}{$0.027 *$} \\
\hline & Range & $9.9-13.4$ & $9.2-13.2$ & \\
\hline \multirow{2}{*}{ Reduction } & Mean \pm SD & $0.8 \pm 0.1$ & $1.2 \pm 0.1$ & \multirow{2}{*}{$<0.001 *$} \\
\hline & Range & $0.5-1.1$ & $0.9-1.5$ & \\
\hline \multicolumn{5}{|c|}{ Value of Tranexamic acid } \\
\hline \multicolumn{2}{|c|}{ Value } & \multicolumn{2}{|c|}{ Mean \pm SE } & $95 \% \mathrm{CI}$ \\
\hline \multicolumn{2}{|c|}{ Reduction difference } & \multicolumn{2}{|c|}{$0.41 \pm 0.02$} & $0.37-0.44$ \\
\hline
\end{tabular}

$\wedge^{\wedge}$ Independent t-test, CI: Confodence interval, *Significant

Table (2) and figure (2) show that: No significant difference between the studied groups regarding preoperative hemoglobin. Postoperative hemoglobin was significantly higher among Tranexamic group than among placebo group ( $p$ value 0.027 ) Hemoglobin reduction was significantly lower among Tranexamic group than among placebo group ( $\mathrm{p}$ value $<0.001$ ). 
Effect of Tranexamic Acid on Blood Loss in Elective Cesarean Delivery

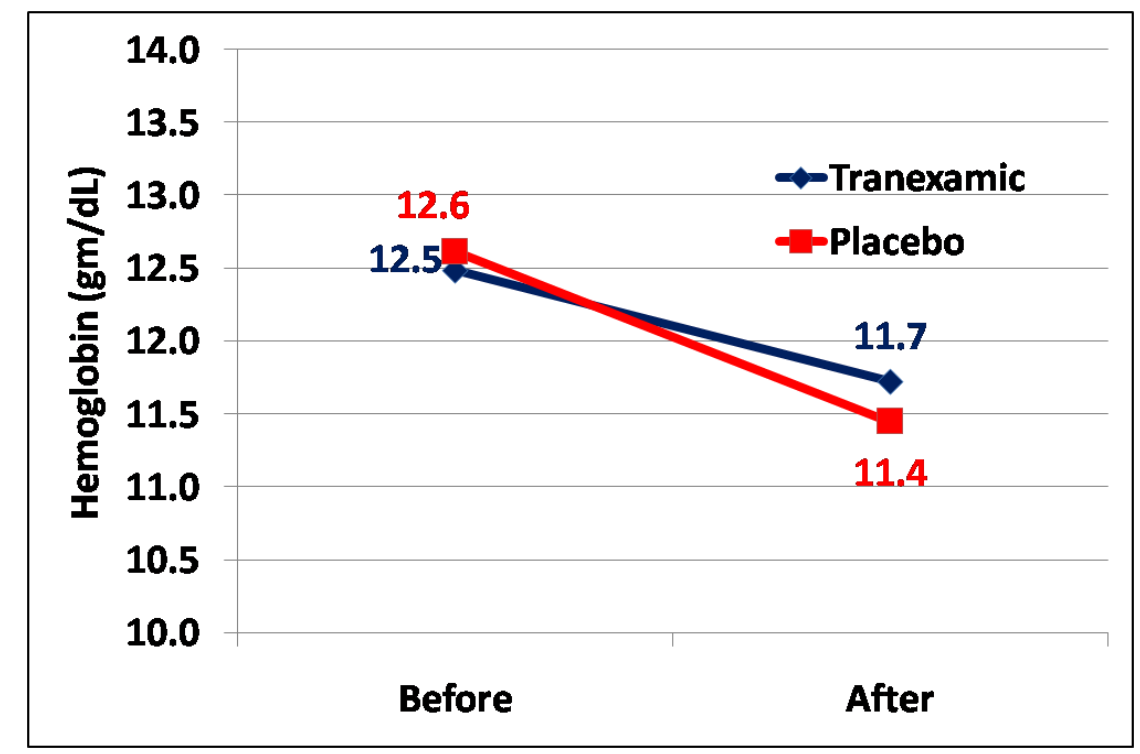

Figure (2): Hemoglobin among the studied groups

Table (2): Hematocrit (\%) among the studied groups

\begin{tabular}{|c|c|c|c|c|}
\hline Variable & Measure & $\begin{array}{c}\text { Tranexamic } \\
(\mathrm{N}=100)\end{array}$ & $\begin{array}{l}\text { Placebo } \\
(\mathrm{N}=100)\end{array}$ & $\wedge \mathbf{P}$ \\
\hline \multirow{2}{*}{$\begin{array}{c}\text { Pre } \\
\text { operative }\end{array}$} & Mean \pm SD & $41.3 \pm 3.2$ & $41.9 \pm 4.1$ & \multirow{2}{*}{0.247} \\
\hline & Range & $31.2-49.3$ & $31.0-51.0$ & \\
\hline \multirow{2}{*}{$\begin{array}{c}\text { Post } \\
\text { operative }\end{array}$} & Mean \pm SD & $38.8 \pm 3.2$ & $37.5 \pm 4.1$ & \multirow{2}{*}{$0.020 *$} \\
\hline & Range & $28.7-46.8$ & $27.2-46.6$ & \\
\hline \multirow{2}{*}{ Reduction } & Mean \pm SD & $2.5 \pm 0.4$ & $4.3 \pm 0.3$ & \multirow{2}{*}{$<0.001$} \\
\hline & Range & $1.7-3.7$ & $3.0-4.9$ & \\
\hline \multicolumn{5}{|c|}{ Value of Tranexamic acid } \\
\hline & & \multicolumn{2}{|c|}{ Mean \pm SE } & $95 \% \mathrm{CI}$ \\
\hline \multicolumn{2}{|c|}{ Reduction difference } & \multicolumn{2}{|c|}{$1.83 \pm 0.05$} & $1.74-1.92$ \\
\hline
\end{tabular}

${ }^{\wedge}$ Independent t-test, CI: Confodence interval, ${ }^{*}$ Significant

Table (2) and figure (3) show that: No statistical significant difference between the research study groups as regards preoperative hematocrit ( $\mathrm{p}$ value $=0.247$ ). Postoperative hematocrit was statistically significantly higher among Tranexamic research group than among placebo research group ( $p$ value $=0.020$ ). Hematocrit reduction was statistically significantly lower among Tranexamic research group than among placebo research group ( $\mathrm{p}$ value $<0.001$ ).

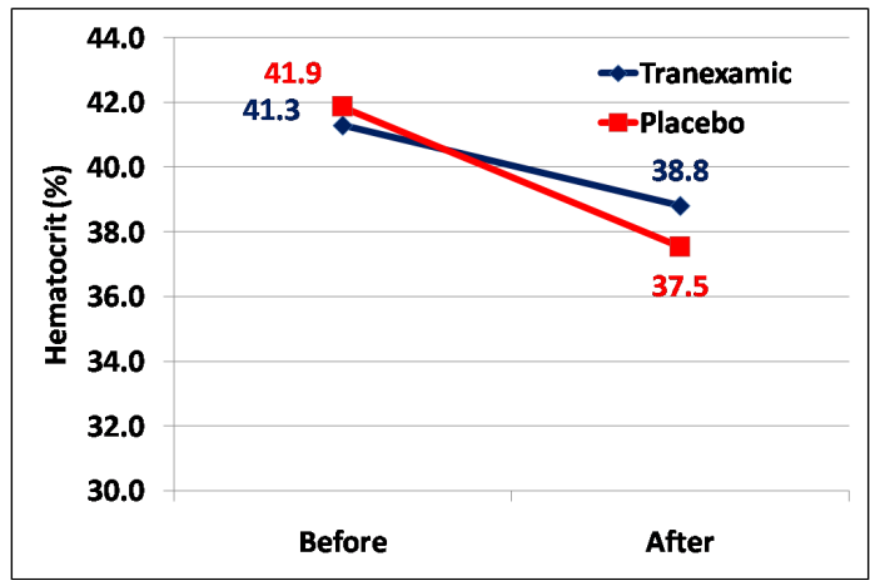

Figure (3): Hematocrit among the studied groups 
Table (3): Blood lossvolume (mL) among the studied groups

\begin{tabular}{|c|c|c|c|}
\hline Measure & $\begin{array}{c}\text { Tranexamic } \\
(\mathbf{N}=\mathbf{1 0 0})\end{array}$ & $\begin{array}{c}\text { Placebo } \\
(\mathbf{N}=\mathbf{1 0 0})\end{array}$ & \multirow{2}{*}{${ }^{\wedge} \mathbf{P}$} \\
\hline Mean \pm SD & $257.6 \pm 42.7$ & $441.9 \pm 65.2$ & \multirow{2}{*}{$<\mathbf{0 . 0 0 1 *}$} \\
\hline Range & $161.3-384.9$ & $307.7-631.5$ & \\
\hline \multicolumn{3}{|c|}{ Value of Tranexamic acid } \\
\hline Value & Mean \pm SE & $\mathbf{9 5 \%}$ CI \\
\hline Blood loss reduction & $184.3 \pm 7.8$ & $168.9-199.7$ \\
\hline
\end{tabular}

^Independent t-test, CI: Confodence interval, *Significant

Table (3) shows that: Blood lossvolume was statistically significantly lower among Tranexamic research group than among placebo research group ( $\mathrm{p}$ value $<0.001$ ).

Table (4): Maternal complications and side effects among the studied groups

\begin{tabular}{|l|c|c|c|c|}
\hline \multicolumn{1}{|c|}{ Conditions } & $\begin{array}{c}\text { Tranexamic } \\
(\mathbf{N = 1 0 0 )}\end{array}$ & $\begin{array}{c}\text { Placebo } \\
\mathbf{( N = 1 0 0 )}\end{array}$ & $\mathbf{P}$ & $\begin{array}{c}\text { RR } \\
\mathbf{( 9 5 \%} \mathbf{C I})\end{array}$ \\
\hline PPH & $2(2.0 \%)$ & $11(11.0 \%)$ & $\# \mathbf{0 . 0 1 0} *$ & $\begin{array}{c}0.29 \\
(0.08-1.06)\end{array}$ \\
\hline Blood transfusion & $1(1.0 \%)$ & $10(10.0 \%)$ & $\# \mathbf{0 . 0 0 5 *}$ & $\begin{array}{c}0.17 \\
(0.03-1.13)\end{array}$ \\
\hline Others & $0(0.0 \%)$ & $0(0.0 \%)$ & -- & -- \\
\hline
\end{tabular}

\#Chi square test, *Significant, RR: Relative risk, CI: Confidence interval

Table (4) show that: PPH and blood transfusion were statistically significantly less frequent among Tranexamic researchgroup ( $\mathrm{p}$ values $=0.010,0.005$ consecutively).

Table (5): Comparison between the studied groups regarding neonatal condition

\begin{tabular}{|c|c|c|c|c|c|}
\hline \multicolumn{2}{|c|}{ Scores } & $\begin{array}{c}\text { Tranexamic } \\
(\mathrm{N}=100)\end{array}$ & $\begin{array}{l}\text { Placebo } \\
(\mathrm{N}=100)\end{array}$ & $\mathbf{P}$ & $\begin{array}{c}\text { RR } \\
(95 \% \mathrm{CI}) \\
\end{array}$ \\
\hline \multirow{2}{*}{$\begin{array}{c}\text { APGAR } \\
1\end{array}$} & Mean \pm SD & $7.9 \pm 1.3$ & $8.0 \pm 1.6$ & \multirow{2}{*}{${ }^{\wedge} 0.496$} & \multirow{2}{*}{--} \\
\hline & Range & $3.0-10.0$ & $3.0-10.0$ & & \\
\hline \multirow{2}{*}{$\begin{array}{c}\text { APGAR } \\
5\end{array}$} & Mean \pm SD & $8.9 \pm 1.0$ & $8.9 \pm 1.3$ & \multirow{2}{*}{${ }^{\wedge} 0.673$} & \multirow{2}{*}{--} \\
\hline & Range & $4.0-11.0$ & $4.0-11.0$ & & \\
\hline \multicolumn{2}{|l|}{ RDS } & $1(1.0 \%)$ & $2(2.0 \%)$ & $\& 1.000$ & $\begin{array}{c}0.66 \\
(0.13-3.31)\end{array}$ \\
\hline \multicolumn{2}{|l|}{ NICU } & $2(2.0 \%)$ & $4(4.0 \%)$ & $\& 0.683$ & $\begin{array}{c}0.66 \\
(0.21-2.06)\end{array}$ \\
\hline \multicolumn{2}{|l|}{ Death } & $1(1.0 \%)$ & $1(1.0 \%)$ & $\& 1.000$ & $\begin{array}{c}1.00 \\
(0.25-4.03) \\
\end{array}$ \\
\hline
\end{tabular}

$\wedge$ Independent t-test, \&Fisher's Exact test, *Significant

Table (5) show that: No significant statistical difference between the studied groups regarding neonatal condition (APGAR 1min, 5min, RDS, NICU, Death, p values =0.496, 0.673, 1.00, 0.683, 1.00, consecutively).

\section{Discussion}

The current research study was conducted to evaluate efficacy of usage of tranexamic acid to decrease blood loss intra-operative in cases undergoing cesarean section deliveries ${ }^{(11)}$.

Intra-operative blood loss and post partum hemorrhage could be avoided through the use of prophylactic utero-tonics by timely and appropriate management. Nevertheless, it has been clearly shown that the administration of uterotonics, and in particular oxytocin is effective in preventing PPH .On the other hand enhancement of chemical hemostasis, a complementary biochemical hemostatic impact could be predictable from the complementary usage of prohemostatic agents e.g Tranexamic acid in its chemical nature a synthetic derivative of the lysine amino acid that have an antifibrinolytic pharmacological impact via 
reversible blockage of the lysine binding sites on plasminogen molecules. Intravenous administration of Tranexamic acid have been classically applied in practice for management and prevention of bleeding issues with encouraging clinical results ${ }^{(12)}$.

As regards the current research study results no statistically significant difference between the studied groups regarding demographic characteristics. (age, BMI, Gestational age, indications for cesarean section $\mathrm{p}$ $=0.174,0.658,0.424,0.893$, consecutively). No significant difference between the studied groups regarding preoperative hemoglobin. Postoperative hemoglobin was statistically significantly higher among Tranexamicresearch group than among placebo research group ( $\mathrm{p}$ value 0.027) Hemoglobin reduction was statistically significantly lower among Tranexamic group than among placebo research group ( $\mathbf{p}$ value $<\mathbf{0 . 0 0 1}$ ).

In addition blood loss volume was statistically significantly lower among Tranexamic research group than among placebo research group ( $\mathrm{p}$ value $<0.001$ ). PPH and blood transfusion were statistically significantly less frequent among Tranexamic research group $(\mathrm{p}$ values $=0.010,0.005$ consecutively).

Finally no statistical significant difference between the studied research groups as regards neonatal condition (APGAR 1min, $5 \mathrm{~min}, \mathrm{RDS}$, NICU, Death, $\mathrm{p}$ values $=0.496$, $0.673,1.00,0.683,1.00$, consecutively).

In the research study of Jianjun $\boldsymbol{e t}$ al. (13) the cases' clinical features and parameters in the two research groups were similar, with no statistical significant difference between the two research groups. The study research group (88 women) was administered Tranexamic acid, whereas the control group 86 women who did not received. In the results the research team of investigators revealed that Tranexamic acid administration statistically significantly decreased the amount of blood volume loss from the end of cesarean section till 2 hours postpartum: $(46.6 \pm 42.7 \mathrm{ml})$ in the study research group versus $(84.7 \pm 80.2 \mathrm{ml})$ in the control research group ( $p<0.01)$, It furthermore statistically significantly decreased the amount of total blood volume from placental delivery to 2 hours postpartum: $(379.2 \pm 160.1 \mathrm{ml})$ in the research study group, $(441.7 \pm 189.5 \mathrm{ml})$ in the control research group $(\mathrm{p}$ value $=0.02)$. Finally post partum hemorrhage was arrested in
65 cases $(75.6 \%)$ in the control research group and in 81 cases $(92.0 \%)$ in the tranexamic acid research group $(\mathrm{p}<0.01)$. No statistically significant abnormal vital signs have been noted after TXA administration. Mild temporary side effects existed more often in the tranexamic acid research group than in the control research group ${ }^{(14)}$.

In another research study similar to the current research study in approach and aim of Sekhavat et al. (15) research team of investigators ., the cases' clinical characteristics in the two research groups were similar, in which there was no statistically significant difference between the two research groups. The study research group involved 45 cases that have been administered tranexamic acid, while the control research group was composed of 45 study subjects that didn't receivetranexamic acid The findings of the research study revealed that Tranexamic acid statistically significantly decreased the blood volume loss from the end of cesarean delivery till 2 hours postpartum: $(28.02+5.53 \mathrm{ml})$ in the study research group $(37.12+8.97 \mathrm{ml})$ versus in the control research group ( $\mathrm{p}$ value $=0.001), \mathrm{Hb}$ $24 \mathrm{~h}$ after cesarean delivery was statistically significantly more in tranexamic research group than control research group $(12.57+1.33 \mathrm{~g} / \mathrm{dl}$ in the tranexamic group and $11.74+1.14 \mathrm{~g} / \mathrm{dl}$ in the control research group, $\mathrm{p}$ value $=0.002$ ). The research team concluded that tranexamic acid as a pharmacological agent could be implementedsafely and efficiently to decrease bleeding occurring during cesarean section performance. Another research study conducted similar to the current research study Tranexamicacid statistically significantly decreased amount of total blood volume loss from placental delivery: $(241.61 \pm 6.77 \mathrm{ml})$ in the study research group, $(510.66 \pm 7.72 \mathrm{ml})$ in the control group $(\mathrm{p} \text { value }=0.0001)^{(\mathbf{1 6})}$.

\section{Conclusion and Recommendations:}

The usage of tranexamic acid before starting a cesarean section is valuable as a prophylaxis against intra-operative and post-partum bleeding issues as displayed by the current research study results. Further research studies are required by integrating greater number of patients and putting in consideration various variables such as racial and ethnic differences .Another issue that is recommended in future research efforts is to consider various case 
scenarios such as previous cesarean and categorization of more possible critical indications of cesarean such as second stage cesarean and emergency cesarean section and time interval of decision to incision as those variables could affect blood volume loss indices. Future research efforts could aid in clinical practice protocols application as regards tranexamic acid usage and safety profiles to be followed on an international levels .

\section{References}

1. Lutomski J, Byrne B, Devane D et al. (2012): Increasing trends in atonic postpartum haemorrhage in Ireland: an 11-year population-based cohort study. BJOG., 119(3):306-14.

2. Blomberg M (2011): Maternal obesity and risk of postpartum hemorrhage. Obstet Gynecol., 118(3):561-8.

3. Hanley GE, Smolina K, Mintzes B et al. (2016): Postpartum Hemorrhage and Use of Serotonin Reuptake Inhibitor Antidepressants in Pregnancy.Obstet Gynecol., (3):553-61.

4. Haelle T (2016): Venlafaxine tied to increased postpartum hemorrhage risk. Medscape Medical News. Available at http://www. medscape. com/viewarticle/858900.

5. Oladapo OT, Fawole B, Blum J et al. (2016): Advance distribution of misoprostol for preventing and treating excessive blood loss after birth. https://extranet.who.int/rhl/fr/node/758 67

6. Gibbins KJ, Albright $\mathrm{CM}$ and Rouse DJ (2012): Postpartum hemorrhage in the developed world: whither misoprostol?. Am J Obstet Gynecol., 208(3):181-3.

7. O'Brien Diop A, Daff B, Sow Met al. (2016): Oxytocin via Uniject (a prefilled single-use injection) versus oral misoprostol for prevention of postpartum haemorrhage at the community level: a cluster-randomised controlled trial. Lancet Glob Health, 4 (1):37-44.

8. Park HS, Shin JH, Yoon HK et al. (2014): Transcatheter Arterial Embolization for Secondary Postpartum Hemorrhage: Outcome in 52 Patients at a Single Tertiary Referral
Center. J Vasc Interv Radiol., 25(11):1751-7.

9. De Lange NM, Lancé MD, Henskens YM et al. (2012): Obstetric hemorrhage and coagulation: an update. Thromboelastography,

thromboelastometry, and conventional coagulation tests in the diagnosis and prediction of postpartum hemorrhage. Obstet Gynecol Surv., 67: 426-35

10. Winter C, Crofts J, Laxton $\mathrm{C}$ et al. (2018): PROMPT: practical obstetrics multi-professional training, course manual second edition. Cambridge University Press: Cambridge.https://www.bookdepositor y.com/PROMPT-Course-ManualCathy-Winter/9781108430296

11. Calvert C, Thomas SL, Ronsmans C et al. (2012): Identifying regional variation in the prevalence of postpartum haemorrhage: a systematic review and meta-analysis. PLoS One, 7:41-47.

12. Kramer MS, Berg C, Abenhaim $\mathrm{H}$ et al. (2013): Incidence, risk factors, and temporal trends in severe postpartum hemorrhage. Am J Obstet Gynecol., 209:449-411.

13. Jianjun $X$, Wei $G$, Yingnan $J$ et al. (2013): Tranexamic acid for the prevention of postpartum hemorrhage after cesarean section: a double-blind randomization trial. Arch Gynecol Obstet., 287:463-468.

14. Matteson KA, Rahn DD, Wheeler TL et al. (2013): Nonsurgical management of heavy menstrual bleeding: A systematic review. Obstet Gynecol., 121:632-43.

15. Sekhavat L, Tabatabaii A, Dalili M et al. (2009): Efficacy of tranexamic acid in reducing blood loss after cesarean section. J Matern Fetal Neonatal Med., 22(1):72-5.

16. Novikova N, Hofmeyr GJ (2010): Tranexamic acid for preventing postpartum haemorrhage. doi:10.1002/14651858.CD007872. 